\title{
Disease with abnormal intracranial vascular network complicated with intracerebral haematoma
}

\author{
KENICHIRO HIGASHI, MITSUNORI HATANO, AND TAKUMA MAZA \\ From the Department of Neurosurgery, Yamaguchi University, School of Medicine, \\ Ube, Yamaguchi-ken, Japan
}

SYNOPSIS A case of so-called Japanese cerebrovascular disease in association with intracerebral haematoma is presented. The patient had had no neurological symptoms before the onset, in spite of an extensive intracranial occlusive vascular process. Diagnosis was established preoperatively and massive haematoma was surgically evacuated from the left frontal lobe. The postoperative course was uneventful and residual neurological deficit was minimal.

Japanese neurosurgeons have recently described a new cerebrovascular syndrome in which cerebral angiography demonstrates certain characteristic features. This syndrome comprises (1) narrowing or occlusion of both internal carotid arteries at the level of the supraclinoid segment, and (2) a fine angiomatous vascular network at the base of the brain.

Since the first report of this unusual cerebrovascular pattern, by Kudo in 1968, similar cases have been reported throughout Japan. In a symposium held during the 18th general assembly of the Japan Medical Association 1971 researchers presented a total of 376 cases of this syndrome occurring in Japan alone (Kudo, 1971). In contrast with the rapid accumulation of reported cases in Japan, only a few reports have appeared in Western medical literature. As far as we know, only 25 cases have been reported outside Japan (Weidner et al., 1965; Simon et al., 1968; Busch, 1969; Lepoire et al., 1969; Taveras, 1969; Urbánek et al., 1970; Vuia et al., 1970; Galligioni et al., 1971; Iraci et al., 1972), and even four of these occurred in Japanese descendants. Because of the apparent higher frequency of occurrence in the Japanese, the disease entity may have some significant racial incidence.

In the adult group with this disease, subarachnoid haemorrhage is a common complication, whereas intracerebral haemorrhage is rare-so rare that only three necropsy cases with massive intracerebral haematoma have been reported (Ando et al., 1967; Maki et al., 1967; Vuia et al., 1970). Hori et al. (1971) reported a case which successfully underwent surgery. Our report is the case of a young adult having the disease, with massive intracerebral haematoma, whom we treated successfully by surgery.

\section{CASE REPORT}

The patient, a 28 year old male farmer, had been in good health and free from neurological symptoms before the onset of illness. On 24 January 1971, while drinking in a public house, he suddenly fell, for no apparent reason. He got up by himself but was unable to walk. He was taken home to bed. The next morning, he was found unconscious in bed and had urinary incontinence. At a hospital, a lumbar puncture revealed bloody spinal fluid. He was then transferred and admitted to our hospital, on 27 January, with a diagnosis of subarachnoid haemorrhage.

On admission, the patient was semicomatose and had right-sided hemiplegia. The blood pressure was $150 / 90 \mathrm{mmHg}$, pulse 64 per min. and regular. There was no anisocoria, and the pupillary light reflex was normal. Deep tendon reflexes of the left lower extremity were increased, and there was bilateral extensor plantar response. A repeat spinal tap disclosed xanthochromic fluid, an opening pressure of $150 \mathrm{~mm} \mathrm{H}_{2} \mathrm{O}$, and a normal protein and cell count. Laboratory examinations of the blood and urine were normal. Radiographs of the skull were also normal.

Left carotid angiography demonstrated a peculiar 


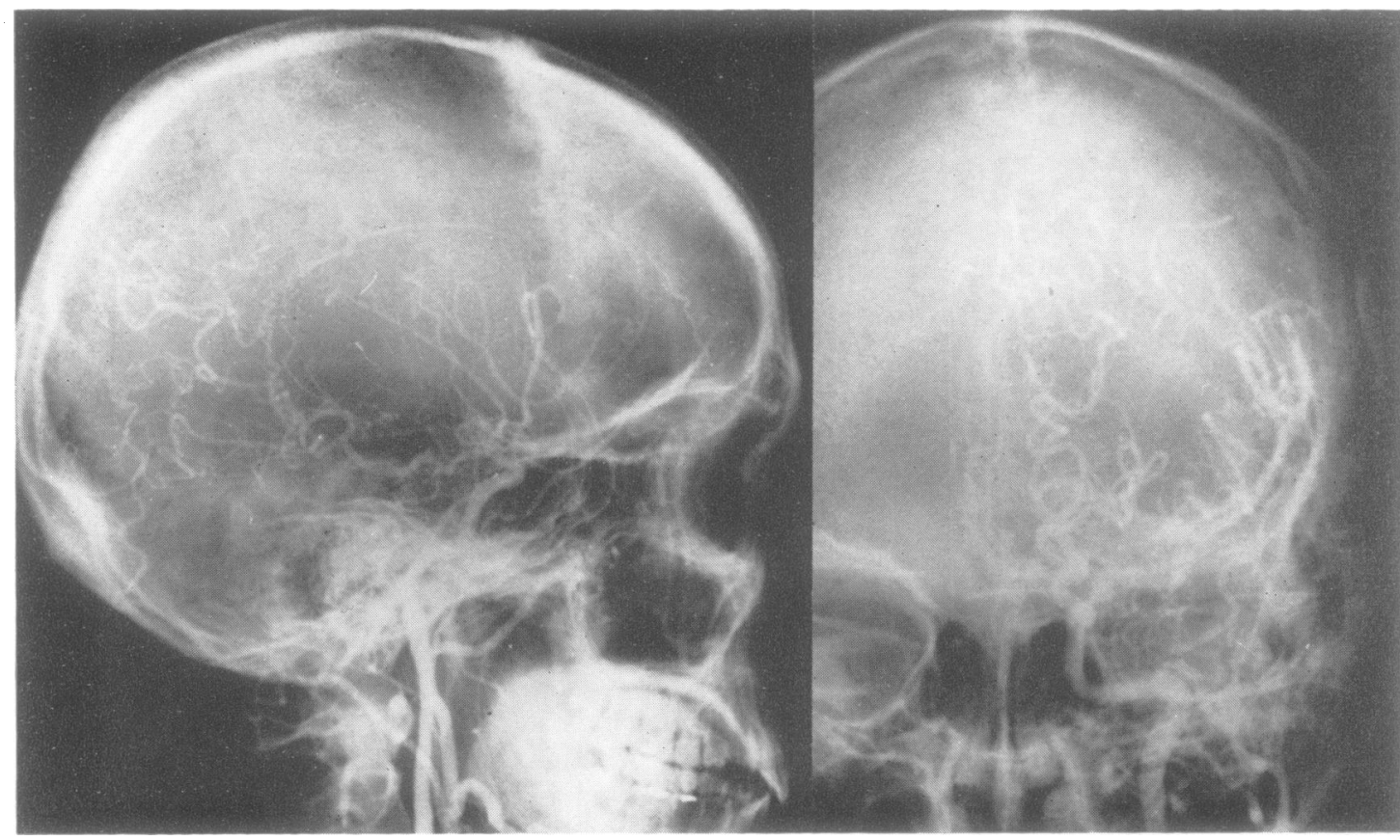

FIG. 1. Preoperative left carotid angiograms show occlusion of the supraclinoid portion of the internal caroti逢 artery. There is an abnormal vascular network just above the site of occlusion, through which ascending branches of the middle cerebral artery are opacified. Faint filling of the proximal anterior cerebral artery is shown which deviates to the right from the midline in $A-P$ view. The posterior communicating and posterior cerebral arteries. $\vec{\oplus}$ are dilated and deviate downwards in lateral view. There is a tortuous end-to-end anastomosis between the peripheral posterior cerebral and the pericallosal arteries. The middle meningeal and occipital arteries provid $\overrightarrow{\vec{e}}$ transdural anastomotic pathways.

vascular anomaly with signs suggesting a spaceoccupying lesion in the left frontal lobe (Fig. 1). The left internal carotid artery was occluded in the supraclinoid portion. Just above the site of occlusion there was an abnormal vascular network through which coursed ascending branches of the middle cerebral artery. Filling of the proximal anterior cerebral artery was minimal but served to demonstrate a curved midline shift. The enlarged posterior communicating and posterior cerebral arteries appeared as if they were a direct continuation of the internal carotid artery. In the lateral view, the posterior cerebral artery was depressed inferiorly, and a tortuous, end-to-end anastomosis existed between the posterior cerebral and pericallosal arteries. Peripheral to the middle meningeal and occipital arteries, one could also see transdural externalinternal carotid anastomoses (rete mirabile). The anteroposterior phlebogram demonstrated a midline shift of the deep cerebral veins, suggesting a mass lesion of the left cerebral hemisphere.
On 1 February, we performed a left, frontoparietal craniotomy. Since the dura mater was extremely tense, we elected to incise the dura mater and perform a transdural tap. At the depth of $3 \mathrm{~cm}$ in the left frontal lobe, we encountered and aspirated $20 \mathrm{ml}$. of brown fluid. After cortical excision in the middle frontal gyrus, we evacuated a large blood clot $(98.5 \mathrm{~g})$ from the white matter of the left frontal lobe. Careful inspection of the wall of the haematoma revealed no haemangiomatous anomaly.

Apnoea occurred two hours after surgery and lasted for about two hours. During that time, respiration was maintained by artificial means. Thereafter, recovery was slow but uneventful. The patient became completely alert on the 10th postoperative day and was walking unassisted by the N 26th day. When discharged two months after surgery, he had mild mental confusion, right $\tilde{N}$ hemiparesis, dysarthria, and right-sided homo- $\underset{\omega}{ }$ nymous hemianopia. When seen 15 months after $Q$ the operation, he had only slight residual monoparesis 0 


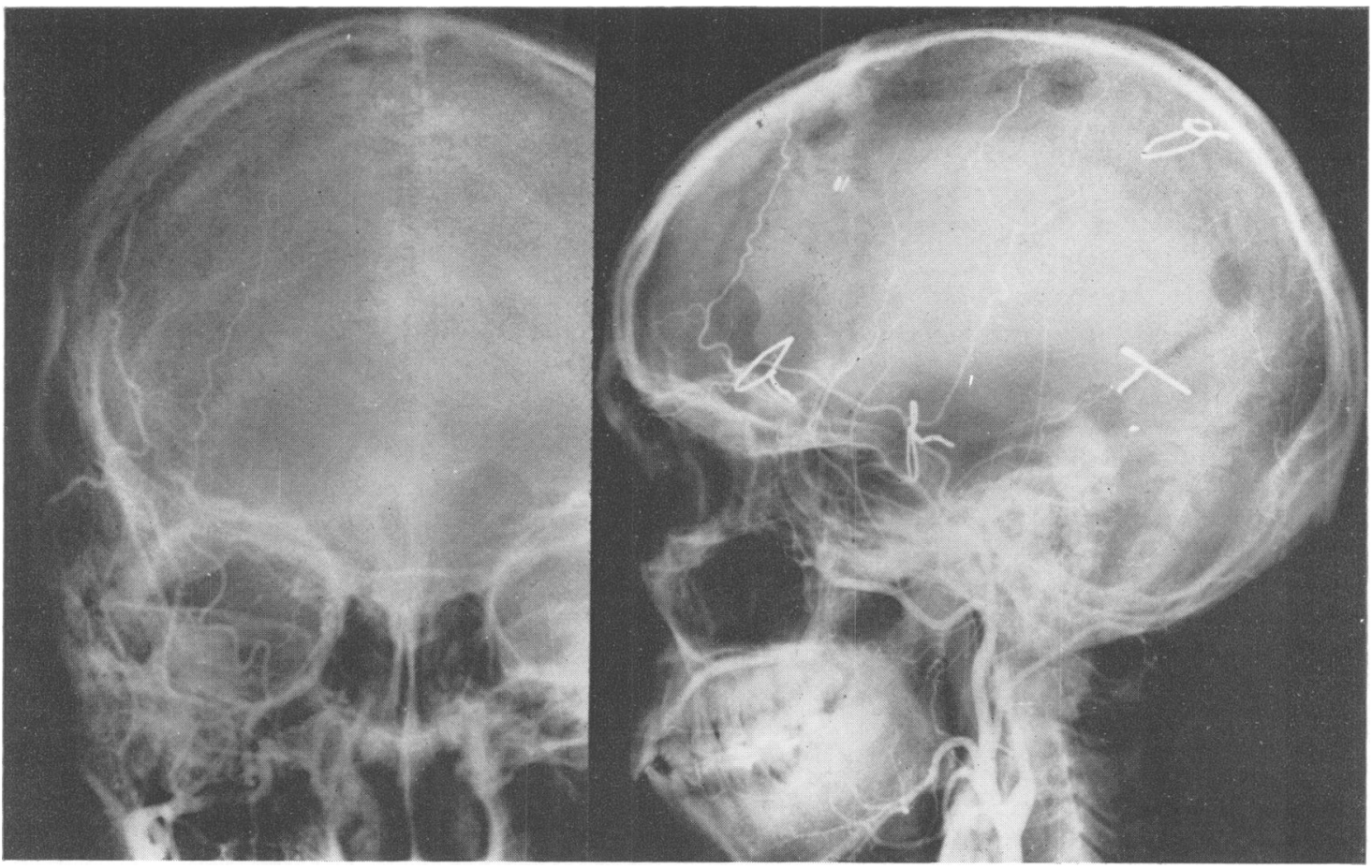

FIG. 2. Postoperative right carotid angiograms. The right internal carotid artery suddenly narrows at $2 \mathrm{~cm}$ peripheral to the carotid bifurcation. Tapered internal carotid artery can be traced until its infraclinoid portion where the fine ophthalmic branch ramifies.

of the right hand and had resumed full-time work as a farmer.

Angiography performed during the postoperative course demonstrated the following features: left carotid angiography (16 March), one-and-a-half months after surgery, revealed improved filling of the anterior cerebral artery which, furthermore, no longer deviated from the midline. Inferior displacement of the posterior cerebral artery also had disappeared. Other findings were the same as on the preoperative left carotid angiogram. On right carotid angiography (17 March), about $2 \mathrm{~cm}$ beyond the bifurcation of the right common carotid, the carotid artery suddenly narrowed and became completely occluded just beyond the origin of the right ophthalmic artery (Fig. 2). Left brachial angiography demonstrated a normal basilar artery. Partial filling of the middle cerebral artery via the dilated posterior communicating artery, and the persistent, abnormal vascular network, just superior to the bifurcation of the basilar artery could be seen. Repeat left carotid angiograms at six and 15 months after surgery revealed an unchanged vascular pattern.

\section{DISCUSSION}

From the identifiable cerebrovascular features of this disease, various writers have employed different terminology, yet the nomenclature remains unstandardized (Kudo, 1968, 1971; Nishimoto and Takeuchi, 1968; Simon et al., 1968; Suzuki and Takaku, 1969; Taveras, 1969; Urbánek et al., 1970; Galligioni et al., 1971; Hori et al., 1971). The aetiology of this entity is unknown, and considerable controversy exists about whether or not the disease belongs to the group of congenital malformations or represents collateral circulation secondary to an obscure occlusive process, perhaps some form of arteritis. Since our patient had no previous symptoms, in spite of extensive intracranial occlusion, we think that the disease could begin early in life, perhaps even during the intrauterine stage.

For the purpose of classification based on symptomatology, patients with this disease 
entity exist in one of two major categories: a younger and an older adult group. Symptoms of the younger group are (1) repeated episodes of cerebral ischaemia, such as hemiplegia, dysphasia, and headache, and (2) mental retardation. However, in the adult group, the most common initial manifestation is subarachnoid haemorrhage (Kudo, 1968, 1971; Nishimoto and Takeuchi, 1968; Suzuki and Takaku, 1969). According to Nishimoto and Takeuchi (1968), subarachnoid haemorrhage occurred in 12 of 23 adults, yet for the younger group, in only two of 73 patients.

Some necropsy reports have referred to the histological findings of enlarged perforating arteries close to the occluded major cerebral arteries (Ando et al., 1967; Maki et al., 1967). Maki and his associates (1967) reported that the perforating vessels at the base of the brain had widened lumina and thin walls, in which the muscle layer was sparse or absent. Occasionally, the internal elastic membrane was also absent. Vuia and associates (1970) found a series of hypoplastic and ectasic vessels within the pia mater and parenchyma, including the haemorrhagic area in their necropsy case which had massive intracerebral haematoma. These thinwalled and enlarged vessels serving as collateral channels are thought to be fragile. Fisher (1959) reported two cases with hypoplasia of the unilateral carotid artery. The patients both died, one because of massive intracerebral haemorrhage and the other due to intraventricular haemorrhage. Both haemorrhages occurred on the side having the hypoplastic artery. Smith et al. (1968) also reported a case with bilateral hypoplasia of the internal carotid arteries in which the patient died from massive intracerebral haemorrhage. In such a patient, the intracerebral vessels have insufficient blood supply from the internal carotid arteries and tend to rupture, thus causing the fatal haemorrhage.

Regarding so-called spontaneous intracerebral haematoma, Margolis et al. (1951) and Krayenbühl and Siebenmann (1965) have emphasized the importance of small vascular malformations as a source of bleeding. It is possible that the unusual angiomatous net-like vessels found in our case caused the intracerebral haemorrhage, although the frequency of rupture of these deep vessels is probably far less than that of pial vessels, which can cause subarachnoid haemorrhage.

All reported cases with intracerebral haematoma in association with this disease died, except for the patient reported by Hori et al. (1971). Accordingly, we believe that surgical evacuation of the haematoma is the treatment of choice. Without surgical intervention, one can expect a fatal outcome.

\section{REFERENCES}

Ando, K., Matsushima, M., Yamamoto, T., Suzuki, Y., Waga, S., Oka, H., and Tsuji, H. (1967). Report of an autopsy case. In $A$ Disease with Abnormal Intracranial Vascular Networks-Spontaneous Occlusions of the Circle of Willis, pp. 89-93. Edited by T. Kudo. Igaku Shoin: Tokyo.

Busch, H. F. M. (1969). Unusual collateral circulation in a child with cerebral arterial occlusion. Psychiatria, Neurologia, Neurochirurgia (Amsterdam), 72, 23-28.

Fisher, C. M. (1959). Early-life carotid-artery occlusion associated with late intracranial hemorrhage. Laboratory Investigation, 8, 680-700.

Galligioni, F., Andrioli, G. C., Marin, G., Briani, S., an Iraci, G. (1971). Hypoplasia of the internal carotid arter associated with cerebral pseudoangiomatosis. Report o\$ 4 cases. American Journal of Roentgenology, 112, 251-262- -

Hori, T., Fukushima, T., Tsuchida, T., Ishijima, B., Manaka S., and Hirakawa, K. (1971). A case of cerebral juxta@ 음 basal telangiectasia with intracerebral hematoma. Braip and Nerve (Tokyo), 23, 1403-1408.

Iraci, G., Marin, G., Andrioli, G. C., and Feltrin, G. (1972) Further observations on the so-called 'Japanese cerebrovascular disease'. American Journal of Roentgenology, 115 , 35-38.

Krayenbühl, H., and Siebenmann, R. (1965). Small vascular malformations as a cause of primary intracerebral hemorrhage. Journal of Neurosurgery, 22, 7-20.

Kudo, T. (1968). Spontaneous occlusion of the circle of Willis. A disease apparently confined to Japanese. Neurology (Minneap.), 18, 485-496.

Kudo, T. (1971). Intracranial abnormal vascular network. In Proceedings of 18th General Assembly of the Japan Medica Association, Tokyo, 1253-1273.

Leeds, N. E., and Abbot, K. H. (1965). Collateral circulation in cerebrovascular disease in childhood via rete mirabile and perforating branches of anterior choroidal and posterior cerebral arteries. Radiology, 85, 628-634.

Lepoire, J., Tridon, P., Montaut, J., Hepner, H., Renard, M., and Picard, L. (1969). Malformations angiomateuses artério-artérielles du système carotidien. Neuro-Chirurgie, $15,5-18$.

Maki, Y., Horie, T., and Nakata, Y. (1967). A report of the autopsied case. In $A$ Disease with Abnormal Intracranial Vascular Networks-Spontaneous Occlusions of the Circle of Willis, pp. 98-104. Edited by T. Kudo. Igaku Shoin: Tokyo.

Margolis, G., Odom, G. L., Woodhall, B., and Bloor, B. M. (1951). The role of small angiomatous malformations in the production of intracerebral hematomas. Journal of Neurosurgery, 8, 564-575.

Nishimoto, A., and Takeuchi, S. (1968). Abnormal cerebro- 
vascular network related to the internal carotid arteries. Journal of Neurosurgery, 29, 255-260.

Prensky, A. L., and Davis, D. O. (1970). Observation of major cerebral vessels in early childhood without neurological signs. Neurology (Minneap.), 20, 945-953.

Simon, J., Sabouraud, O., Guy, G., and Turpin, J. (1968). Un cas de maladie de Nishimoto. A propos d'une maladie rare et bilatérale de la carotide interne. Revue Neurologique, 119, 376-383.

Smith, K. R. Jr., Nelson, J. S., and Dooley, J. M. (1968) Bilateral 'hypoplasia' of the internal carotid arteries. Neurology (Minneap.), 18, 1149-1156.

Suzuki, J., and Takaku, A. (1969). Cerebrovascular 'Moyamoya' disease. Archives of Neurology, 20, 288-299.
Taveras, J. M. (1969). Multiple progressive intracranial arterial occlusions: a syndrome of children and young adults. American Journal of Roentgenology, 106, 235-268.

Urbánek, K., Fárková, H., and Klaus, E. (1970). NishimotoTakeuchi-Kudo disease: case report. Journal of Neurology, Neurosurgery, and Psychiatrv, 33, 671-673.

Vuia, O., Alexianu, M., and Gabor, S. (1970). Hypoplasia and obstruction of the circle of the Willis in a case of atypical cerebral hemorrhage and its relationship to Nishimoto's disease. Neurology (Minneap.), 20, 361-367.

Weidner, W., Hanafee, W., and Markham, C. H. (1965). Intracranial collateral circulation via leptomeningeal and rete mirabile anastomoses. Neurology (Minneap.), 15, 39-48. 